\title{
The CD15 Immunohistochemical Marker of Hodgkin-Reed-Sternberg cells - a Perspective
}

\author{
Daniel Benharroch*, Parwin Zarin and Karen Nalbandyan \\ Soroka University Medical Centre and Faculty of Health Sciences, Ben-Gurion University of the Negev, Israel
}

Received: March 17, 2018; Published: April 05, 2018

*Corresponding author: Daniel Benharroch, Soroka University Medical Center and Faculty of Health Sciences, Institute of Pathology, 1, Rager Blvd, PO Box 151, Beer-Sheva 84101, Israel, Tel: 972-507579140; Email: danielbenharroch1@gmail.com

\section{Commentary}

\section{Precis}

A historical perspective of the expression of CD15 in classic Hodgkin lymphoma is presented. CD15 antigens expression has ranged over the years from $27 \%$ to $90 \%$ and more. The CD15 expression, although showing a sensitivity and specificity of less than $90 \%$ for Hodgkin-Reed-Sternberg (HRS) cells [1], has been used for several decades, together with CD30 to confirm the diagnosis of the presently classified classic Hodgkin lymphoma (cHL). Historically, the tumor cells of this malignancy have been considered to express from 75 to $90 \%$ positivity for this marker, using manual immunophenotyping and non-sialyl-CD15 antibodies [2]. This variance might have been due in part to the fixation process (stronger staining with the B5 fixation when compared with neutral formalin); and in part due to the anti-CD15 antibody employed (LeuM1 - Becton Dickinson; 80H5 - Immunotech, Marseille; C3D1 clone, DakoM1 - Dakopatts and others - the classic anti-CD15 antibodies). When the automated stainer, Ventana Benchmark (Ventana Medical Systems, Tucson, AZ), was introduced around 2009, some noted that the usual CD15 antibodies showed a much reduced staining capacity, and the HRS cells positivity in some labs reached an all times low of around $40 \%$.

At this point, several modifications had to be introduced. Moreover, it soon became obvious that the Ventana Benchmark was meeting difficulties with the secondary IgM antibodies used for CD15 immunostaining. The novel anti-CD15 antibodies, which have been introduced since then, include among others, the MMA clone, Cell Marque Corp., Hot Springs, USA; the BY87 clone, Novocastra Labs, Newcastle-on-Tyne, UK and the Carb-3 clone by Dako, Glostrup, Denmark. When using these antibodies, staining of the HRS cells with the Ventana Benchmark did improve, but not to the level reached at the time of the manual Immunohistochemical method [3]. Of three anti-CD15 clones used with the Ventana Medical Systems, the MMA clone was found in one study to be the most effective for staining HRS cells, and it detected tumor cells in 32 of 39 cases [4]. In a more recent study, a proportion higher than expected of cHL cases disclosed a CD15 expression as low as $37 \%$ [5].

A further extensive investigation based on different anti-CD15 monoclonal antibodies and involving mainly cHL, revealed that among the Carb-3, MMA and BY87 clones, the Carb-3 was by far superior as an immune histo chemical reagent. Overall, however, in between 24 and $50 \%$ of the cases, the staining quality was poor [6]. Recently, we have found a staining level of about $65 \%$ by using the Carb-3 anti-CD15 antibody which gave the best results for automated immunostaining in our laboratory (data not shown). Especially low levels of CD15 expression (as low as 27\% for mixed cellularity $\mathrm{CHL}$ ) have been reported in cHL from Taiwan. As the results were pooled from three major hospitals from the capital the primary anti-CD15 antibodies characteristics were critical, mainly Carb-3 [7]. It is of note, that studies preceding the use of the Ventana Benchmark, showed that a marked proportion of the LeuM1 and 80H5 CD15-negative cHL cases, corresponded almost precisely to the cases showing sialyl-CD15 positive HRS cells which were associated with a worse prognosis $[2,8,9]$.

A further study disclosed a significantly more positive expression of sialyl-CD15 in primary refractory cHL when compared with a control group, as well as with early and late relapsed disease [10]. A more recent investigation regarding CD20 over-expression in HRS cells of cHL showed that the non-sialyl-CD15 positive expression, but the negative expression of sialyl-CD15, correlated 
with low/nil levels of CD20 [11]. This differential expression of the sialyl- and non-sialyl anti-CD15 will in turn determine the fate of the immunostaining and will reflect by itself the patient clinical status. Nevertheless some reports presented often high expressions of CD15 [6]. Thus, indications have been presented, that, in addition to technical problems - fixation; the novel anti-CD15 antibodies and adaptation of the IgM secondary antibodies - consistently negative CD15 expression might possibly be reflect an increased proportion of refractory cHL cases [10].

Moreover, together with the evolution depicted above, a large number of unrelated markers have added to the pertinence of the diagnosis of cHL: PAX5, SP34, Thermo Scientific; MUM1, MRQ - 43, Cell Marque; CD25, 4C9, Neomarkers; fascin, 55k-2, Cell Marque; HLA-DR, CR3/43. And only occasionally, will a case occur, for which a positive staining for CD15 will sway the balance of the markers panel, to favor cHL. The inconstant expression of CD15 antigens in the last several decades has sustained the diagnosis of cHL through fluctuating levels (Table 1).

Table 1: The anti-CD15 antibodies in historical perspective for classic Hodgkin lymphoma.

\begin{tabular}{|c|c|c|c|}
\hline $\begin{array}{c}\text { CD15 antigens } \\
\text { era }\end{array}$ & $\begin{array}{c}\text { anti-CD15 (non- } \\
\text { sialyl) antibody }\end{array}$ & $\begin{array}{c}\text { Percent } \\
\text { Positive }\end{array}$ & References \\
\hline $\begin{array}{c}\text { Historical } \\
\text { Perspective }\end{array}$ & $\begin{array}{c}\text { LeuM1 (Becton and } \\
\text { Dikinson) }\end{array}$ & $75-90 \%$ & $2,8,9$ \\
\hline & $\begin{array}{c}80 \text { H5 (Immunotech, } \\
\text { Marseille) }\end{array}$ & $80-92 \%$ & 2 \\
\hline & $\begin{array}{c}\text { C3D1 (Dako, Glostrup, } \\
\text { Denmark) }\end{array}$ & $75-85 \%$ & 4 \\
\hline "Ventana" & $\begin{array}{c}\text { MMA (Cell Marque } \\
\text { Corp., USA) }\end{array}$ & $37-85 \%$ & 4,6 \\
\hline & Carb-3 (Dako) & $50-100 \%$ & 6 \\
\hline BY87 (Novocastra & $57-75 \%$ & 4,6 \\
\hline Present UK) & Carb-3 (Dako) & & \\
\hline & MMA (Cell Marque) & & \\
\hline
\end{tabular}

In a variable proportion of cHL cases, the novel immunophenotypic markers in use to confirm the diagnosis may have rendered the CD15 antigen redundant. However, the high specificity of anti-CD15, even as compared with that of CD30, will preclude such an attitude. It is most probable, that the inconsistency found over the years, regarding the expression of CD15, and which may range between 22 and 100\% [9], might be accounted for by the very wide assortment of anti-CD15 antibodies on the market [1].

\section{References}

1. Hall PA, D Ardenne AJ (1987) Value of CD15 immunostaining in diagnosing Hodgkin's disease: a review of published literature. J Clin Pathol 40(11): 1298-1304.

2. Benharroch D, Dima E, Levy A, Ohana-Malka O, Ariad S, et al. (2000) Differential expression of sialyl- and non-sialyl-CD15 antigens on Hodgkin-Reed-Sternberg cells: significance in Hodgkin disease. Leuk Lymphoma 39(1-2): 185-194.

3. Hsu SM, Raine L, Fanger H (1981) Use of avidin-biotin peroxidase complex $(\mathrm{ABC})$ in immunoperoxidase technique. J Histo chemistry Cyto chemistry 29(4): 577-580.

4. Pellegrini W, Bresciani G, De Zorzi A, Marocolo D, Ungari M, et al. (2007) MMA monoclonal antibody is a superior anti-CD15 reagent for the diagnosis of Hodgkin lymphoma? Haematologica 92(5): 708-709.

5. Weiss LM (2013) A typical phenotypes in classic Hodgkin lymphoma. Surg Pathol Clin 6(4): 729-742.

6. Røge R, Nielsen S, Vyberg M (2014) Carb-3 is the superior antiCD15 monoclonal antibody for immunohistochemistry. Appl Immunohistochem Mol Morphol 22(6): 449-458.

7. Chuang SS (2017) In frequent expression of CD15 by classical Hodgkin's lymphoma in Taiwan. J Clin Pathol 70(2): 183-184.

8. Hsu SM, Ho YS, Li PJ, Monheit J, Ree HJ, et al. (1986) L\&H variants of Reed-Sternberg cells express sialylated Leu M1 antigen. Am J Pathol 122(2): 199-203.

9. Von Wasielewski R, Mengel M, Fischer R, Hansmann ML, Hübner K, et al. (1997) Classical Hodgkin disease. Clinical impact of immunophenotype. Am J Pathol 151(4): 1123-1130.

10. Benharroch D, Pilosof S, Gopas J, Levi I (2012) Primary refractory and relapsed classical Hodgkin lymphoma - Significance of differential CD15 expression in Hodgkin-Reed-Sternberg cells. J Cancer 3: 322-327.

11. Benharroch D, Nalbandyan K, Lazarev I (2015) CD20 over-expression in Hodgkin-Reed-Sternberg cells of classical Hodgkin lymphoma: the neglected quest. J Cancer 6(11): 1155-1159.
This work is licensed under Creative Commons Attribution 4.0 License

Submission Link: https://biomedres.us/submit-manuscript.php

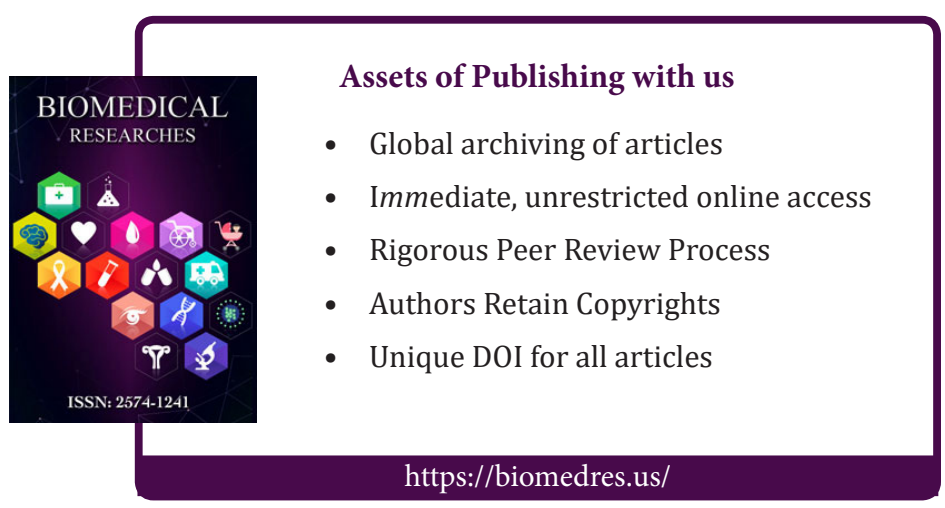

